\title{
A INDISCIPLINA: UM OBSTÁCULO NO ENSINO-APRENDIZAGEM
}

\author{
Cláudia Cristina Santana Nascimento Araújo'
}

RESUMO: O presente artigo busca apresentar um estudo acerca da indisciplina, que se torna um obstáculo no ensino-aprendizagem. Assim, mediante pesquisa bibliográfica constatou-se que a indisciplina possibilita a construção do conhecimento, expressão de sentimentos, desfavorecendo a interação aprendizagem e conhecimento. $O$ tipo de pesquisa realizada foi à revisão bibliográfica e, justifica-se este estudo por meio das contrariedades existentes no cotidiano do educador na atuação do ensino-aprendizagem e, os dilemas existentes no exercício do ensino-aprendizagem. Os principais teóricos pesquisadores para a concretização dos estudos foram estudiosos renomeados na área e que estes ressaltarem a importância de trabalhar mediando o processo de ensino-aprendizagem dentro de uma sala com alunos indisciplinados. Busca-se verificar as ações e intervenções para a diminuição da indisciplina e como essas subversões influenciam no aprendizado escolar. Por outro lado, é possível minimizar os problemas da indisciplina por meio de um trabalho de parceria entre a escola, família e sociedade. No entanto existem algumas dificuldades nesse caminho que estão associadas aos fatores como a falta de tempo da família para participar mais da comunidade escolar e acompanhar o desenvolvimento do filho. É um trabalho de parceria escolafamília, pois ambas são responsáveis pela formação de valores morais que integram o meio social e a atuação dos cidadãos. Assim, demonstra a necessidade de meios de intervenções tanto para alunos e pais como professores e sociedade, porque o problema da indisciplina é também social que influencia no ambiente escolar e consequentemente na formação educacional.

PALAVRAS-CHAVES: Ensino-aprendizagem. Escola. Família. Indisciplina.

${ }^{1}$ Aluna do curso de Mestrado em ciências da educação 


\section{INTRODUÇÃO}

Este artigo consiste em um relatório de leituras com embasamento de alguns estudiosos na área da indisciplina. Sendo estes enfoques pertinentes para serem discutidos e refletidos, mas não como processos isolados, e sim intricados. E tem por objetivo primordial discutir acerca da indisciplina tida como obstáculo no ensino-aprendizagem.

Diante desse obstáculo de ensino-aprendizagem que é a indisciplina, torna-se relevante identificar as forças que impulsionam e retêm a dinâmica das ações e interações dos alunos dentro da sala de aula e a partir daí criar propostas viáveis à realização de uma prática pedagógica eficiente.

É preciso que se motive um ambiente escolar harmonioso no qual os alunos saibam se relacionar respeitosamente tanto dentro como fora da instituição, de modo a se tornar cidadão ativo e participativo na sua sociedade.

Para alavancar o estudo foi utilizado como ponto de partida um estudo de revisão bibliográfica sobre a temática, pesquisa essa de cunho qualitativa, a qual se procura responder o motivo e como evitar a indisciplina na escola, já que é vista como obstáculo do ensino-aprendizagem.

Assim, a discussão que se pretende perpetrar é de defender a ideia de integrar escola, família e comunidade para a garantia de um ensino de qualidade, com base na formação de valores, cidadania e na qualidade de vida. Além, de ressaltar as relações estabelecidas entre as pessoas e o espaço.

Partindo da visão feita em estudos bibliográficos, percebe-se a necessidade de desenvolver uma análise sobre a participação dos cidadãos em torno dos princípios que norteiam a Educação como um meio social.

Sendo que se trata de uma pesquisa bibliográfica de cunho qualitativa e o foco é a qualidade da mesma, em prol de uma educação que trata dos direitos de todos de forma igualitária, que para ter êxito precisa da participação da família para uma melhor qualidade de ensino e erradique a indisciplina na escola.

Nessa ótica, a participação efetiva dos pais no processo de aprendizagem facilita a prática pedagógica dos professores e de todos que fazem a instituição progredir. Isso evidencia a responsabilidade, que a escola tem em incentivar e apoiar sem articulação família e escola. 
Por isso, a questão da parceria entre família e escola reúne importantes pontos que servem de pontos para a reflexão sobre os benefícios a serem alcançados nessa relação.

\title{
2. CAMINHOS METODOLÓGICOS
}

Para o desenvolvimento deste trabalho, optou-se por uma abordagem qualitativa, por meio da pesquisa bibliográfica baseada em estudos, a metodologia utilizada foi à revisão de literatura, com pesquisa em livros, artigos científicos e monografias publicadas em bases online.

Gil (2006, p. 65) ressalta que "a pesquisa bibliográfica é desenvolvida a partir do material já elaborado constituído principalmente de livros e artigos científicos". As fontes consideradas para realização dessa pesquisa são artigos científicos do Google Acadêmico e bases de dados em sites de Universidades brasileiras.

O tipo de abordagem é qualitativa, pois à mesma será feita com base em análises e opiniões dos autores sobre os desafios e possiblidades: mediação do coordenador pedagógico na formação continuada dos professores. As informações coletadas serão retiradas de livros, artigos e textos estudados a cerca da indisciplina escolar com foco no ensino-aprendizagem.

Segundo Bogdan e Biklen (1994) a abordagem qualitativa é uma metodologia de investigação que enfatiza a descrição, a indução, a teoria fundamentada e o estudo das percepções pessoais.

Tal abordagem, para esses autores, tende a assumir um cunho descritivo e interpretativo dos dados qualitativos coletados por meio dos estudos realizados, tendo em vista a natureza do problema e o objetivo proposto. De acordo com Fernando Rey (2005, p.103),

\begin{abstract}
A pesquisa qualitativa caracteriza-se pela construção de um modelo teórico como via de significação da informação produzida, a qual não está fragmentada em resultados parciais associados aos instrumentos usados, mas está integrada em um sistema cuja inteligibilidade é produzida pelo pesquisador.
\end{abstract}

Pelos estudos realizados podemos perceber que as pesquisas qualitativas possuem várias metodologias, ou seja, usam uma grande variedade de procedimentos e instrumentos para coleta de dados. 
Acreditamos que os resultados colhidos possam dar subsidio para compreender o processo de controle a indisciplina. Enfim, esperamos que o trabalho estimulem reflexões aos leitores que se interesse a cerca da temática e lhe possibilitem compreender a importância da participação família escola e comunidade.

\section{RESULTADO E DISCUSSÃO DOS DADOS}

Um dos grandes desafios pedagógicos da atualidade tem sido lidar com a indisciplina escolar, problema este presente ao longo da história, mas que nos últimos tempos tem preocupado pais, professores e todos aqueles envolvidos e interessados nas questões da educação. Lidar com a indisciplina nas escolas e especialmente na sala de aula não é um trabalho fácil, pois muitas das decisões tomadas pelas instituições de ensino têm sido paliativas, ou seja, insignificantes.

Toda instituição, para um bom funcionamento precisa de regras de organização, ajuste, ordenamento, tendo em vista que se todos os envolvidos realizam ao seu modo suas atuações gera uma desordem dentro do ambiente escolar, envolvendo crianças, adolescentes e jovens que estão em formação. É preciso da intervenção da família, da escola e demais ambientes de socialização e ensino.

As escolas têm tido grande dificuldade em relação ao ensino, pois são inúmeras as dificuldades encontradas pelos educadores, desde a falta de participação nas aulas, a recusa de muitos alunos em aceitar as regras estabelecidas, a desmotivação pelo ensino-aprendizagem, a falta do acompanhamento da família no desenvolvimento dos filhos.

Esses são algumas das razões que têm atrapalhado o andar do trabalho pedagógico. Pois, comportamentos indisciplinados culminam no baixo resultado de aproveitamento do aluno que é indisciplinado e dos colegas que foram prejudicados.

A presença da família na vida escolar do educando é essencial para conter alunos indisciplinados, que acabam trazendo consigo, para a escola, sentimentos e problemas acumulados no seu lar, que muitas vezes refletem no seu comportamento escolar. Cabe destacar ainda que a família exerce o papel 
crucial na formação de valores indispensáveis para seguir às regras do espaço formal que é a escola.

Por outro lado, tem sido uma realidade a família delegar funções da educação dos filhos aos professores, o que não funciona, pois são instituições educativas, mas com autonomias diferentes.

Assim, o desafio de educar tem sido um grande obstáculo enfrentado, principalmente pelo professor em sala de aula, espaço este cada vez mais diversificado, sem uma boa base familiar, sem a segurança social, o apoio psicológico para atuarem em situações de conflitos e em muitos casos são crianças, adolescentes e jovens em situação de risco.

Isso significa que a indisciplina é um problema que cresce e existem diversos fatores que contribuem para esse episódio, como por exemplo, antes no ensino tradicional a indisciplina era punida com castigos, muitos deles físicos, professores a autoridade máxima e o detentor do conhecimento. Porém, na atualidade isso não é aceitável e o aluno também tem acesso a informação e pode atuar na construção do conhecimento, por meio de questionamentos.

No entanto, o espaço escolar continua a ser regido por normas de funcionamento assim como a sociedade. Segundo Magalhães Jr (2002), "a disciplina no espaço escolar, constitui-se em uma ferramenta que auxilia no estabelecimento da "ordem" e representa os interesses de um grupo".

Daí, a importância dos limites, das regras de conduta ensinados no ambiente familiar, bem como conhecer a realidade social do aluno, pois a forma como o indivíduo vive marcada por conflitos acaba sendo reproduzida na sala de aula. Sobre isso Weil, (1984) reforça:

O comportamento das crianças no ambiente escolar e em casa é, na verdade, uma reação às atitudes de seus pais. Foi constatado que a maioria dos problemas de comportamento, como ausência de atenção e agressividade, é reflexo da conduta dos pais. Uma criança, por exemplo, que não consegue, em sala de aula, ficar parada em momento nenhum, mostrado-se sempre nervosa, brigona, agressiva com os colegas, sempre mal arrumada, cadernos rasgados, pode ser que uma das causas para tudo isso seja um relação conflituosa com a família ou a relação, também conflituosa, entre os pais, os quais brigam o tempo todo na frente dos filhos e acabam descontando na criança, com desprezo ou indiferença, com agressões físicas ou verbais (WEIL, 19884, p. 47). 
Isso significa que a escola, a família e o meio social em que vivem influenciam na forma como os indivíduos são educados e como a ação de uma dessas instâncias pode refletir na outra. Desse modo, alunos indisciplinados levam os professores a ficarem cada vez mais cansados e estressados, por não conseguirem cumprir o seu papel de educador.

Outro ponto relevante está relacionado ao excesso de liberdade que é resultado da falta de limites. Os celulares com internet são um exemplo, pois trata-se de um avanço, que permite a criança pesquisar e ter acesso a informação, mas por outro lado tem dificultado o trabalho dos professores com falta de atenção e uso indevido desse recurso, como comportamentos de rebeldia como som ligado, enquanto é trabalhado a explicação dos conteúdos, a alta atração pelas mídias desvia a concentração e contribui para que as aulas planejadas sejam vistas como chatas e desvalorizadas.

As atitudes possíveis a serem tomadas pelo professor nessa situação poderia ser no caso extremo tomar o celular, porém, como estabelece o artigo 1.634 do Código Civil não é recomendável que o professor retire do aluno o celular, pois ao fazê-lo poderá ser criada uma situação de confronto pedagógico, pessoal e social, que tende a agravar os conflitos.

E com isso o aluno sente que não poderá ser punido severamente e em casa também, porque não tem limites, isso justifica muitas das causas de comportamentos indisciplinados.

\footnotetext{
É impossível colocar à parte escola, família e sociedade, pois, se o indivíduo é aluno, filho e cidadão, ao mesmo tempo, a tarefa de ensinar não compete apenas à escola, porque o aluno aprende também através da família, dos amigos, das pessoas que ele considera significativas, dos meios de comunicação, do cotidiano. Sendo assim, é preciso que professores, família e comunidade tenham claro que a escola precisa contar com o envolvimento de todos (SOUZA, 2008, p. 1).
}

Evidencia-se, então, a significativa importância da parceria entre escola e família, pois assim como é necessário que a família conheça as dificuldades dos seus filhos na escola, é importante também que a equipe escolar também conheça a situação difícil em que o aluno vive em casa. Nas palavras de Tiba (1996, p.166) afirma ainda, "a educação ativa formal é dada pela escola. Porém, a educação global é feita a outras mãos: pela escola, pai e mãe e pelo próprio adolescente". 
Com as mudanças na estrutura econômica e social muitas famílias colocam a responsabilidade de educar seus filhos nas mãos de outras pessoas. É uma realidade da sociedade atual ter famílias desestruturadas que não possuem autoridade sobre os filhos ou mesmo veem a escola como inimiga, onde pais não compactuam do mesmo objetivo de educação escolar. No entanto, mesmo diante de tantas mudanças, inclusive na família e na escola, os papéis não podem ser invertidos.

Assim, a prática educativa tem sido um grande desafio enfrentado pelos professores em sala de aula com turmas cada vez mais diversificadas com ausência de uma base orientado da família, sem a segurança social em que muitas crianças, adolescentes e jovens estão a mercê da violência e risco social.

Os comportamentos de indisciplina podem ser uma problemática de estudo nos cursos de formação de educadores, pois "se o professor tem dificuldade em lidar com toda essa complexidade do ambiente escolar e com a diversidade, certamente, uma parcela da responsabilidade cabe aos cursos de formação de professores" (OLIVEIRA, 2005, p. 6).

Fica claro então, a necessidade da competência do professor tanto formal como política em adequar o seu projeto de aula à necessidade da sala de aula, como afirma Demo (1993):

Todos os apoios didáticos, importantes em si, dependem da capacidade do professor, inclusive aproveitamento das adequações físicas dos estabelecimentos, do material escolar etc. O único livro didático insubstituível é o próprio professor. Deve star de tal modo bem formado, que, se necessário for, ele mesmo prepara texto de português, exercício de matemática, projeto de planejamento etc. ( $p$. 89).

Dessa forma, é necessário que prevaleça a formação crítica e consciente do professor para atuar com problemas característicos do seu tempo. Atualmente, surge discutir problemas de comportamento em sala de aula, nos cursos de formação docente, tendo em vista as mudanças significativas que a relação professor aluno vem sofrendo no decorrer do tempo.

Para Oliveira e Reis (2005, p. 16): 
O essencial seria que os cursos de formação propiciassem aos professores discussões que abrangessem os problemas comportamentais e de relação professor-aluno a partir de várias perspectivas e que levassem os futuros professores a conhecerem a pratica, a vivenciá-la.

Dessa forma, as questões voltadas para o comportamento dos alunos são essenciais na formação de professores, pois as discussões teóricas dão o embasamento para a prática, porém não se deve limitar à visão utópica, posto à educação é feita de desafios.

$\mathrm{Na}$ sociedade atual, ser professor não é somente apropriar-se de um conteúdo e apresentá-lo aos alunos, mas é necessário também conhecer o educando, pois faz parte do papel e do desempenho pelo professor saber 0 que ensinar, para que e para quem, ou seja, como o aluno vai utilizar o que aprendeu na escola em sua prática social.

O docente tem um papel social e político insubstituível, mesmo diante das diversas tecnologias de acesso a informação. Ainda é imprescindível a atuação humanizadora, reflexiva e crítica do professor, que gerencia o conhecimento até o aluno.

Assim, reforça Cury (2003, p.65), que os educadores, apesar das suas dificuldades, são insubstituíveis, porque a gentileza, a solidariedade, a tolerância, a inclusão, os sentimentos e todas as áreas da sensibilidade não podem ser ensinadas por máquinas, mas somente por seres humanos.

Sob esse ponto de vista, o professor é uma autoridade na educação e na formação dos indivíduos, que deve ter autonomia nas suas atitudes e receber o apoio da família nesse processo, pois são parceiros na construção do cidadão. Além dessa parceria, a formação do docente é muito importante como coloca Oliveira (2005):

O bom senso e a experiência podem ajudar no gerenciamento de sala de aula. Manter os alunos sempre ocupados com atividades que Ihes interessem e que exijam concentração pode ser um fator fundamental para evitar a indisciplina. O professor deveria ter condições de preparar sua aula antes de entrar em sala procurando prever a dosagem, o nível de dificuldade e a duração de cada atividade, evitando seu excesso ou a ociosidade dos alunos (OLIVEIRA, 2005, p. 65). 
Desse modo, é importante a presença da família junto à escola como meio de disciplinar, educar e formar o indivíduo, porém não pode deixar de destacar que ao tratar a escola não fica restrito ao papel do professor, mas também a presença dos profissionais da administração escolar, a direção e a coordenação pedagógica.

Existe a necessidade de problemas como indisciplina escolar serem discutidos não só nas reuniões de pais e mestres ou nos horários de estudo dos professores, mas também durante a construção do Projeto Político Pedagógico da escola, documento em que estão os princípios e metas que são discutidas e rediscutidas pelos membros da escola.

Nesse sentido, a realidade das escolas atualmente está marcada pela falta de clareza sobre o que fazer pelos professores, diretores, coordenadores e acabam culminando em regras que muitas vezes são impostas aos alunos e são constituídas em sua maioria apenas de deveres que não são cumpridos.

No entanto, a atuação pedagógica do professor regida pela ética não permitirá que o aluno tome atitudes conflitantes com o espaço escolar, precisando definir limites, intervenção e ensinamentos que os alunos necessitam para viver e trabalhar em um mundo em evolução, bem como orientá-los para a vida.

O trabalho com a moral, em termos de educação, está em conhecer as regras que são pautadas em princípios e conseguir encontrar nesses princípios um valor. Então, para conter a indisciplina não significa impor regras doutrinárias, mesmo que na maioria das vezes, usar do autoritarismo em sala de aula tem servido ainda como medida paliativa, como uma das formas de minimizar os problemas de indisciplina.

A criança, desde cedo, sente a necessidade de questionar, e na prática educativa, o educador precisa encontrar respostas para os questionamentos de forma saudável, porque muitas vezes os atos de indisciplina são ações de revolta, de protesto aos conflitos na escola, na família e na sociedade, para chamar a atenção do educador.

Assim, o conhecimento da prática educativa faz com que o professor tenha consciência de que ensinar hoje não é expor conteúdos e esperar que estes estudantes ajam como a geração no século passado, pois a realidade e o contexto são outros. Os alunos querem experimentar, serem desafiados, 
descobrirem novas possibilidades e sem não entender o contexto de cada disciplina não é possível ajudá-los.

Nesse sentido, é preciso compreender o conceito de liberdade do aluno para não se transformar em indisciplina, pois com o efeito da evolução das condições gerais de vida, em todos os meios, as crianças tornaram-se mais independentes, menos dispostas a obedecer à autoridade dos adultos. Na sala de aula isso tem se manifestado em atos como a falta de respeito dos alunos, gritos, desordens como se tudo estivesse ao alcance ao seu tempo e hora.

Assim, ressalta-se a necessidade de os cursos de formação de professores contemplarem as discussões sobre a indisciplina escolar, instrumentalizando seus acadêmicos para tratar das questões de indisciplina que certamente estarão inseridas nas escolas.

\section{CONSIDERAÇÕES FINAIS}

Visto que a prática educativa para se constituir em um contexto de desenvolvimento buscando conhecimento integral do ser, mais do que mediação de conhecimento ou de competência cognitivas, mais inclusive, a mediação e a transformação de seus aspectos psicossociais.

Incluso nessa perspectiva de inovação e transformação é que a escolafamília poderá contribuir expressivamente para melhorias das práticas escolares de forma competente, reflexiva e crítica. Provocando nos educadores, profissionais da educação e a família a entenderem que a consciência do mundo e a consciência de si é a conclusão dentro do movimento de busca.

Essas mudanças são resultado das contínuas transformações sociais, culturais e tecnológicas do mundo contemporâneo que têm demandado uma nova proposta de educação capaz de oferecer um novo modelo de escola e, consequentemente, que tenha um novo perfil de educador para atender às necessidades do educando dentro desta nova era.

A prática educativa, a organização do espaço e, os recursos da escola precisam despertar o interesse do aluno, pois não é mais possível ensinar 
como antes, em que os alunos deixavam-se influenciar pela autoridade exercida pelo professor de ensinar.

$\mathrm{Na}$ sociedade atual, o aluno já não se influencia pelo professor que ensina, desvalorizando a escola como fonte de acesso ao conhecimento, do saber. As mídias disponibilizam conteúdos que despertam maior interesse do aluno, muitas das vezes, questiona-se a competência do professor para lecionar a disciplina tanto pelos educandos quanto pelos pais.

Em outro momento do passado, os alunos iam para a escola e estavam prontos para se adaptarem aos métodos dos professores, atualmente o professor deve adequar-se ao encontro dos interesses e da linguagem dos alunos.

A formação docente é tão importante, pois norteia todo trabalho pedagógico, para o educador que tem o conceito de que o aluno disciplinado é aquele passivo, logo vai se identificar com os aspectos cognitivos e comportamentais nessa concepção.

Isso é reflexo da formação, pois o aluno que interage, questiona, e que mesmo que agita a organização da sala com conversa e questionamentos dos conteúdos não significa que ele seja indisciplinado. Diante do exposto, acredita-se que o trabalho realizado foi de grande relevância para 0 conhecimento acerca da indisciplina diante ao processo ensino e aprendizagem. 


\section{REFERÊNCIAS BIBLIOGRÁFICAS}

BOGDAN, R.; BIKLEN, S. Investigação qualitativa em educação: uma introdução à teoria e aos métodos. Tradução de Maria João Alvarez, Sara Bahia dos Santos e Telmo Mourinho Baptista. Portugal: Porto, 1994.

CURY, Augusto Jorge. Pais brilhantes, professores fascinantes. Rio de Janeiro: Sextante, 2003.

DEMO, Pedro. Desafios Modernos da Educação. Petrópolis, RJ: Editora Vozes, 1993.

MINAYO, Maria Cecilia de Souza (Org.); et al. Pesquisa social: teoria, método e criatividade. 24. Ed. Petrópolis, RJ: Vozes, 1994.

OLIVEIRA, M. C. P; REIS, M. S. A. (In) disciplina: uma problemática no cotidiano escolar. In: Simpósio de Educação do Sudoeste Goiano, 4., 2005, Jataí. Anais. 2005. p.1-9.

OLIVEIRA, Maria Isete de. Indisciplina Escolar: determinantes, consequências e ações. Brasília: Líber Livro, 2005.

OLIVEIRA, R. L. G.; GOLBA, M. A. M. Reflexões sobre Indisciplina Escolar e Formação de Professores. In: Seminário Internacional de Educação, 12., 2008, Cachoeira do Sul. Anais. Editora: ULBRA, 2008. p. 34-41.

REY, Fernando González. Pesquisa Qualitativa e subjetividade: Os processos de construção da informação. São Paulo, Pioneira Thomson Learnina, 2005.

SOUZA. A.P. A importância da parceria entre família e escola no desenvolvimento educacional. Disponível em http://www.rieoei.org/1821.htm Acesso em 27 de fevereiro 2018.

TIBA, I. Disciplina, limite na medida certa. São Paulo: Editora Gente, 1996.

WEIL, P. G. A Criança, o lar e a escola - guia prático de relações humanas e psicológicas para pais e professores. Petrópolis: Vozes, 1984. 